\title{
Mechanisms of improvement of respiratory failure in patients with COPD treated with NIV
}

\author{
Annabel H Nickol ${ }^{1,2}$ \\ Nicholas Hart ${ }^{1,3}$ \\ Nicholas S Hopkinson' \\ Carl-Hugo Hamnegård ${ }^{4}$ \\ John Moxham ${ }^{5}$ \\ Anita Simonds' \\ Michael I Polkey' \\ 'Respiratory Muscle Laboratory, \\ Royal Brompton Hospital, London, \\ UK; ${ }^{2}$ Oxford Centre for Respiratory \\ Medicine, Churchill Hospital, Oxford, \\ UK; ${ }^{3}$ The Lane Fox Unit, St Thomas' \\ Hospital, London, UK; ${ }^{4}$ Department \\ of Pulmonary Medicine and Clinical \\ Physiology, Sahlgrenska University, \\ Gotenborg, Sweden; ${ }^{5}$ Respiratory \\ Muscle Laboratory, King's College \\ London School of Medicine, King's \\ College Hospital, London, UK
}

\begin{abstract}
Background: Noninvasive ventilation (NIV) improves gas-exchange and symptoms in selected chronic obstructive pulmonary disease (COPD) patients with hypercapnic respiratory failure. We hypothesized NIV reverses respiratory failure by one or all of increased ventilatory response to carbon-dioxide, reduced respiratory muscle fatigue, or improved pulmonary mechanics.

Methods: Nineteen stable COPD patients (forced expiratory volume in one second $35 \%$ predicted) were studied at baseline (D0), 5-8 days (D5) and 3 months (3M) after starting NIV.

Results: Ventilator use was 6.2 (3.7) hours per night at D5 and 3.4 (1.6) at $3 \mathrm{M}(\mathrm{p}=0.12)$ Mean (SD) daytime arterial carbon-dioxide tension $\left(\mathrm{PaCO}_{2}\right)$ was reduced from $7.4(1.2) \mathrm{kPa}$ to $7.0(1.1) \mathrm{kPa}$ at D5 and $6.5(1.1) \mathrm{kPa}$ at $3 \mathrm{M}(\mathrm{p}=0.001)$. Total lung capacity decreased from $107(28) \%$ predicted to $103(28)$ at D5 and $103(27) \%$ predicted at $3 \mathrm{M}(\mathrm{p}=0.035)$. At D5 there was an increase in the hypercapnic ventilatory response and some volitional measures of inspiratory and expiratory muscle strength, but not isolated diaphragmatic strength whether assessed by volitional or nonvolitional methods.

Conclusion: These findings suggest decreased gas trapping and increased ventilatory sensitivity to $\mathrm{CO}_{2}$ are the principal mechanism underlying improvements in gas-exchange in patients with COPD following NIV. Changes in some volitional but not nonvolitional muscle strength measures may reflect improved patient effort.
\end{abstract}

Keywords: COPD; hypercapnic respiratory failure; NIV; pulmonary mechanics; ventilatory drive

\section{Introduction}

In selected COPD patients, noninvasive ventilation (NIV) plus long-term oxygen therapy (LTOT) improves arterial carbon-dioxide tension $\left(\mathrm{PaCO}_{2}\right)$, sleep-time and efficiency and health related quality of life compared to LTOT alone (Meecham-Jones et al 1995; Clini et al 2002). Despite these observations, and widespread NIV use in hypercapnic restrictive thoracic disease (Kerby et al 1987; Carroll and Branthwaite 1988; Ellis et al 1988; Leger et al 1994), its use in COPD remains controversial (Hill 2000; Rossi 2000). This is partly because in previous studies less than half of COPD patients continued to use NIV at 3 (Leger et al 1994) and 5 years (Simonds and Elliott 1995). It may also reflect the poor prognosis of end-stage COPD, with 5 and 10 year survival rates of 30 and $8 \%$ respectively (Robert et al 1983).

Improved understanding of how NIV delivered at night improves day-time gas-exchange and symptoms may aid patient selection and NIV implementation. In a previous study of patients with restrictive thoracic disease (Nickol et al 2005) we demonstrated NIV increases ventilatory sensitivity to carbon-dioxide, but is not associated with increased respiratory muscle strength that may be brought about by relief of fatigued respiratory muscles, and it does not improve pulmonary mechanics.

This study aims to investigate these three potential mechanisms of action of NIV, and compare COPD and restrictive thoracic disease patients. 


\section{Methods}

This prospective, observational study was approved by the hospital's ethics committee, and written informed consent obtained. Consecutive stable COPD patients with symptomatic hypercapnic respiratory failure (for example nocturnal awakening, daytime somnolence and morning headaches), admitted to hospital for elective initiation of nocturnal NIV were invited to participate. Ventilators were chosen according to availability and generally set up in pressure-control mode (mean [SD] inspiratory pressure 23.5 [4.7] and positive expiratory pressure of 5-6 $\mathrm{cm} \mathrm{H}_{2} \mathrm{O}$ in 10 patients). The following ventilators were used: NIPPY-1 ( $n=4$; B\&D Electromedical, UK), VPAP-II ST ( $\mathrm{n}=10$; ResMed, UK) and BREAS-PV '102' ( $n=1)$, '401' $(n=1)$ and '403' $(n=2$; BREAS Medical, Sweden), BiPAP-Harmony ( $\mathrm{n}=1)$ and BromptonPac volume control ( $\mathrm{n}=1$; Brompton Hospital, London). Patients were studied at baseline (D0), 5-8 days (D5) and three months after commencing NIV (3M), including clinical review, subjective sleepiness using the Epworth sleepiness score (ESS), daytime arterial blood gases (after 20 minutes rest seated breathing air), overnight pulse oximetry (pulse oximeter 200-E, Nellcor, USA) and transcutaneous $\mathrm{CO}_{2}$ pressure $\left(\mathrm{PtcCO}_{2}\right.$; Radiometer $\mathrm{A} / \mathrm{S}$, Denmark). Ventilator pressures were titrated upwards as tolerated to improve nocturnal hypoventilation, reflected by peak nocturnal $\mathrm{PtcCO}_{2}$ and daytime $\mathrm{PaCO}_{2}$. Besides lung function all tests were performed at the same time of day for each patient starting at 10 am or $2 \mathrm{pm}$, and took approximately $2 \frac{1}{2}$ hours. All data except compliance were acquired, stored and analyzed on a Macintosh computer using customized software (Labview ${ }^{\mathrm{TM}}$; National Instruments, USA). Patients refrained from caffeine for at least two hours before the study. The following tests were carried out with gastric and esophageal balloon catheters in situ.

The hypercapnic ventilatory response (HCVR) was determined using a re-breathing technique (Read 1967). Patients breathed in a closed circuit from a $6 \mathrm{~L}$ anesthetic bag, filled with $5 \% \mathrm{CO}_{2}$, balance oxygen for four minutes, whilst their end-tidal $\mathrm{CO}_{2}$ and ventilation were measured breath by breath. Two HCVR runs were performed, separated by at least 30 minutes, and the mean of the two runs used. The following measures of respiratory muscle strength were determined as described previously; (Polkey et al 1995) sniff nasal inspiratory pressure (SNIP), sniff esophageal pressure (Sniff Poes), maximum inspiratory and expiratory mouth pressure (maximum inspiratory mouth pressure [PiMax] and maximum expiratory mouth pressure [PeMax]), cough gastric pressure (Pga), sniff transdiaphragmatic pressure (Sniff Pdi) and twitch transdiaphragmatic pressure (TwPdi), assessed using bilateral anterolateral phrenic nerve magnetic stimulation. Full pulmonary function was measured at D0 and $3 \mathrm{M}$ and lung volumes alone at D5. Static lung and chest wall compliance were determined using a quasistatic technique and standard lung function testing equipment (Jaegar Compact Body, Viasys Systems Ltd, UK).

\section{Data analysis}

Statistical analysis was carried out using SPSS V10 (SPSS Inc, Chicago, IL), and values expressed as mean (SD). Statistical significance was defined as $p<0.05$. Paired t-tests and one-way repeated measures of analysis of variance were used to compare variables measured on two and three occasions respectively, and linear regression analysis for examining the relationship between changes in variables. Mann Whitney-U test was used for between group comparisons. All data was normally distributed (Kolmogorov-Smirnov test).

\section{Results \\ Patient characteristics}

Twenty-four COPD patients were invited to participate. Four declined, and one with severe disease (forced expiratory volume in one second $\left[\mathrm{FEV}_{1}\right] 15 \%$ predicted) could not continue after baseline studies due to dyspnea. Baseline data of the remaining 19 patients are shown in Table 1. Eighteen underwent repeat studies at D5 (one was unable to attend) and 16 at $3 \mathrm{M}$ (two died; one had a stroke).

Tobacco smoking was the etiology of COPD in 17/19 patients; two had fixed airflow limitation due to longstanding asthma. Two patients were transferred directly from other hospitals, one following an acute exacerbation 6 weeks previously, and one following a progressive decline associated worsening cor pulmonale. The other 17 patients were admitted electively from home, and were stable over the preceding three months. All patients had co-morbidities; 13 were clinically obese (body mass index [BMI] $>30 \mathrm{~kg} / \mathrm{m}^{2}$ ), three were overweight (BMI $25-29.9 \mathrm{~kg} / \mathrm{m}^{2}$ ), and only three were slim $\left(\mathrm{BMI}<25 \mathrm{~kg} / \mathrm{m}^{2}\right)$. Nine out of 19 gave a history of snoring and daytime somnolence suggesting COPD/obstructive sleep apnea (OSA) cross-over syndrome. In line with standard UK practice we did not attempt to clarify whether obstruction or hypoventilation predominated. Eleven had stable cardiovascular disease, three had type II diabetes mellitus, and two had coexistent restrictive lung disease (bilateral diaphragm weakness and kyphoscoliosis) judged to be minor in comparison to COPD on the basis of lung function tests. Patients with a history suggesting COPD/OSA cross-over syndrome were heavier with smaller lung volumes. Two patients were 
Table I Mean (SD) baseline characteristics $(\mathrm{n}=19)$ for all patients with COPD, and subdivisions without and with clinical evidence of OSA

\begin{tabular}{|c|c|c|c|c|}
\hline Characteristics & All patients $(n=19)$ & No OSA $(n=10)$ & OSA $(n=9)$ & No OSA cf OSA ( $p$ value) \\
\hline \multicolumn{5}{|l|}{ Anthropometrics } \\
\hline Sex, M: F & II:08 & $6: 4$ & $5: 4$ & - \\
\hline Age (years) & $62(12)$ & $59(15)$ & $65(6)$ & 0.60 \\
\hline Pack years (years) & $48(29)$ & $44(26)$ & $52(32)$ & 0.72 \\
\hline BMI $\left(\mathrm{kg} / \mathrm{m}^{2}\right)$ & $35(8)$ & $30(6)$ & $39(8)$ & $0.019 *$ \\
\hline $\mathrm{PaO}_{2}(\mathrm{kPa})$ & $7.3(1.0)$ & $7.4(1.2)$ & $7.3(0.8)$ & 0.66 \\
\hline $\mathrm{PaCO}_{2}(\mathrm{kPa})$ & $7.4(1.2)$ & $7.6(1.6)$ & $7.1(0.7)$ & 0.60 \\
\hline Peak noct $\mathrm{PtcCO}_{2}(\mathrm{kPa})$ & $13.2(4.5)$ & $13.9(5.0)$ & $12.2(3.8)$ & 0.78 \\
\hline ESS (out of 24) & $13(6)$ & $14(4)$ & $12.1(6.7)$ & 0.44 \\
\hline \multicolumn{5}{|l|}{ Drive } \\
\hline HCVR $(1 / \mathrm{min} / \mathrm{kPa})$ & $4.1(3.2)$ & $4.5(4.1)$ & $3.6(2.0)$ & 0.80 \\
\hline \multicolumn{5}{|l|}{ Muscle strength } \\
\hline $\operatorname{PiMax}\left(\mathrm{cmH}_{2} \mathrm{O}\right)$ & $48(15)$ & $51(13)$ & $44(16)$ & 0.36 \\
\hline Poes $\left(\mathrm{cmH}_{2} \mathrm{O}\right)$ & $64(12)$ & $64(13)$ & $64(12)$ & 0.96 \\
\hline $\operatorname{PeMax}\left(\mathrm{cmH}_{2} \mathrm{O}\right)$ & $91(39)$ & $82(38)$ & $10 \mid(4 I)$ & 0.32 \\
\hline Sniff Pdi $\left(\mathrm{cmH}_{2} \mathrm{O}\right)$ & $76(23)$ & $68(19)$ & $84(26)$ & 0.38 \\
\hline TwPdi $\left(\mathrm{cmH}_{2} \mathrm{O}\right)$ & $7(5)$ & $5(4)$ & $8(6)$ & 0.57 \\
\hline \multicolumn{5}{|l|}{ Lung function } \\
\hline FEV (\% Predicted) & $35(16)$ & $29(13)$ & $42(16)$ & 0.14 \\
\hline $\mathrm{FEV}_{1}: \mathrm{FVC}$ & $43(18)$ & $39(20)$ & $47(15)$ & 0.37 \\
\hline TLC (\% Predicted) & III (25) & $123(19)$ & $98(24)$ & $0.024^{*}$ \\
\hline FRC (\% Predicted) & $|5|(36)$ & $|7|(30)$ & $|3|(3 \mid)$ & $0.008^{*}$ \\
\hline RV (\% Predicted) & $193(4 \mid)$ & $221(29)$ & $166(32)$ & $0.003^{*}$ \\
\hline \multicolumn{5}{|l|}{ Static compliance } \\
\hline $\mathrm{C}_{\text {Lung }}\left(\mathrm{mls} / \mathrm{cmH}_{2} \mathrm{O}\right)$ & $110(47)$ & $112(49)$ & $107(49)$ & 0.73 \\
\hline $\mathrm{C}_{\mathrm{cW}}\left(\mathrm{mls} / \mathrm{cmH}_{2} \mathrm{O}\right)$ & $\mid 28(4 \mid)$ & $142(37)$ & II 4 (44) & 0.24 \\
\hline
\end{tabular}

Abbreviations: BMI, body mass index; COPD, chronic obstructive pulmonary disease; ESS, Epworth sleepiness score; FEV , forced expiratory volume in I second; FRC, functional residual capacity; $\mathrm{HCVR}$, hypercapnic ventilatory response; OSA, obstructive sleep apnea; $\mathrm{PaCO}_{2}$, arterial carbon-dioxide tension; $\mathrm{PaO}$, arterial oxygen tension; PeMax, maximum expiratory mouth pressure; PiMax, maximum inspiratory mouth pressure; $\mathrm{Ptc} \mathrm{CO}_{2}$, transcutaneous $\mathrm{CO}_{2}$ pressure; SD, standard deviation; Sniff Pdi, sniff transdiaphragmatic pressure; TwPdi, twitch transdiaphragmatic pressure.

already on LTOT and seven were started on it with NIV as oxygen had not previously been tolerated due to excessive hypercapnia. One patient had oxygen supplementation at night only, and another had it as required during the day.

\section{Use and efficacy of NIV}

Ventilator use information where available, was highly variable, with numerically greater adherence at D5 than $3 \mathrm{M}$ (not significant, $\mathrm{p}=0.12$ ). 12/16 patients used NIV for more than 4 hours at D5, but only $2 / 10$ at 3M. 8 patients with use available at D5 and 3M used NIV 6.2 (3.7) hours per night at D5 and $3.4(1.6)$ at 3M. Use was not greater in those with OSA compared to those without at D5 (7.3 [4.2] hours per night versus 6.5 [2.4], $\mathrm{p}=0.87)$ or at $3 \mathrm{M}(4.9$ [2.4] versus $2.7[0.5], \mathrm{p}=0.15)$.

There was a progressive fall in $\mathrm{PaCO}_{2}$, from $7.4(1.2) \mathrm{kPa}$ at $\mathrm{D} 0,7.0(1.1) \mathrm{kPa}$ at D5 and 6.5 (1.1) $\mathrm{kPa}$ at 3M. There was also a fall in arterial bicarbonate and ESS, and rise in arterial oxygen tension $\left(\mathrm{PaO}_{2}\right)$ (Figure 1). Peak nocturnal transcutaneous $\mathrm{CO}_{2}$ was measured at D0, D5, and $3 \mathrm{M}$ in 15,17 , and 14 patients, respectively. It fell from 13.2 (4.5) at baseline to 9.3 (3.1) at $\mathrm{D} 5$ and $8.4(1.6) \mathrm{kPa}$ at $3 \mathrm{M}(\mathrm{p}=0.001)$. There was a significant relationship between the fall in $\mathrm{PaCO}_{2}$ and fall in bicarbonate at D5 $\left(\mathrm{p}<0.001 ; \mathrm{r}^{2}=0.72\right)$ and a trend towards a relationship at $3 \mathrm{M}\left(\mathrm{p}=0.09 ; \mathrm{r}^{2}=0.19\right)$. Hydrogen ion concentration did not change significantly $(\mathrm{p}=0.42)$, at $40.2(2.5) \mathrm{mM} / \mathrm{L}$ at D0, $39.0(2.2) \mathrm{mM} / \mathrm{L}$ at $\mathrm{D} 5$ and $39.0(5.0) \mathrm{mM} / \mathrm{L}$ at $3 \mathrm{M}$.

\section{Ventilatory response to carbon-dioxide}

18/19 patients carried out HCVR testing at baseline and on at least one further occasion. The mean (SD) HCVR was $4.1(3.2) 1 / \mathrm{min} / \mathrm{kPa}$ at baseline, 5.1 (3.5) $1 / \mathrm{min} / \mathrm{kPa}$ at $5 \mathrm{D}$ and $5.0(3.4) \mathrm{l} / \mathrm{min} / \mathrm{kPa}$ at $3 \mathrm{M}$ (Figure 2). This increase was not significant overall from D0 to D5 to $3 \mathrm{M}(\mathrm{p}=0.23)$, 
$\mathrm{PaCO}_{2}(\mathrm{kPa})$

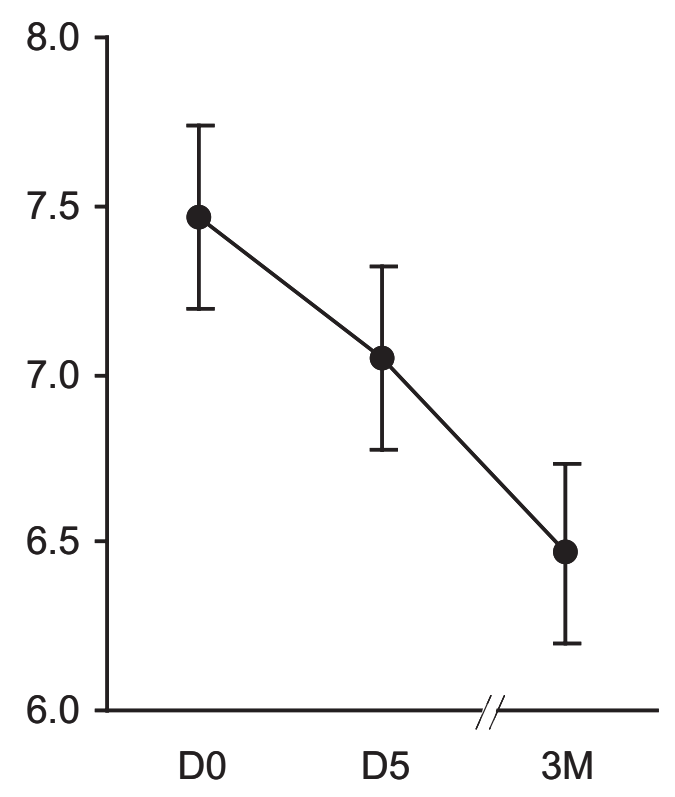

Bicarbonate $(\mathrm{mM} / \mathrm{I})$

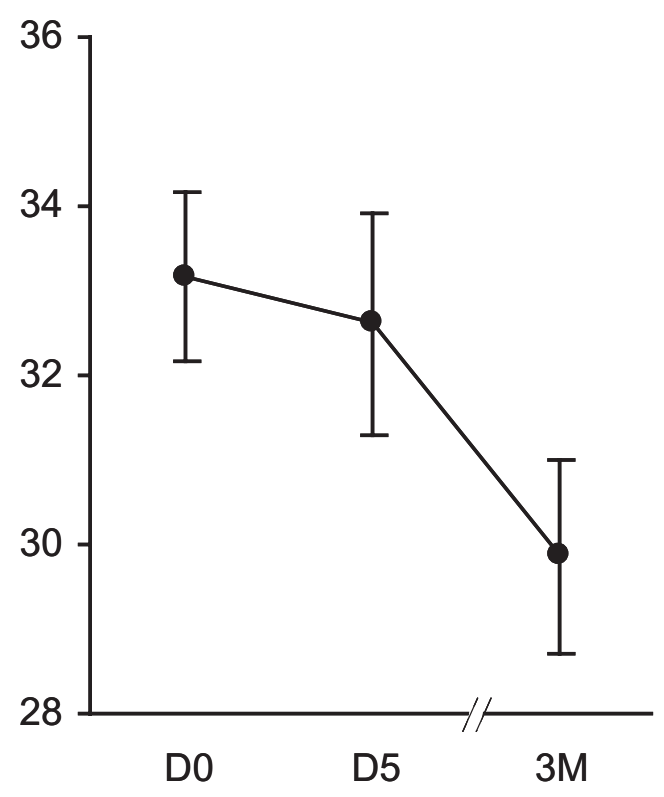

$\mathrm{PaO}_{2}(\mathrm{kPa})$

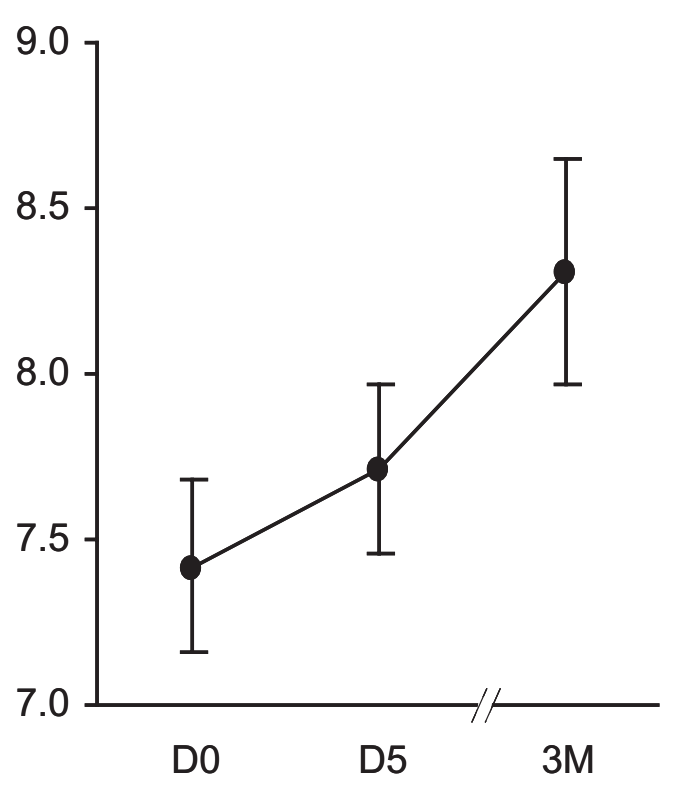

Epworth Sleepiness Score

(Out of 24)

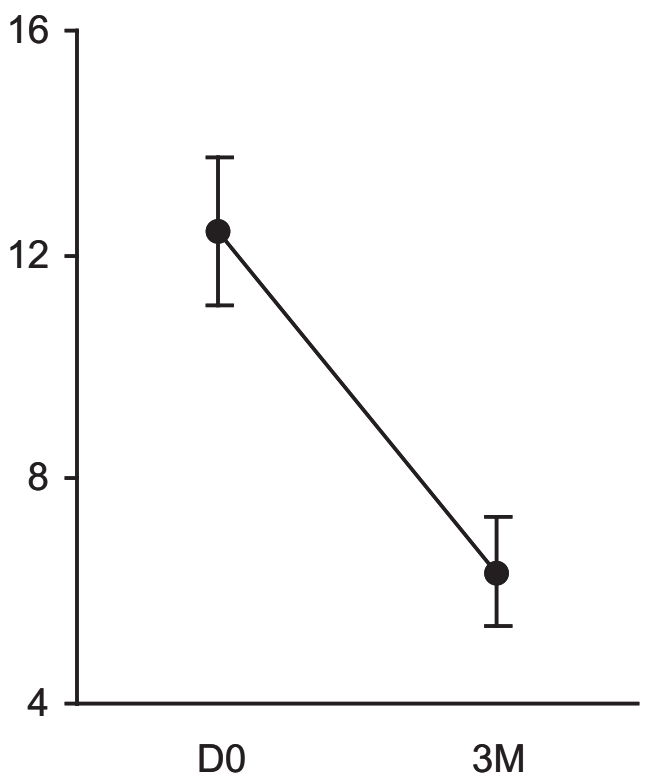

Figure I Effect of NIV on arterial blood gases and ESS. Mean (SEM) $\mathrm{PaCO}_{2}, \mathrm{PaO}_{2}$, arterial bicarbonate and ESS at D0, D5 and $3 \mathrm{M}$ are shown. There was a significant fall in $\mathrm{PaCO}_{2}(p=0.00 \mathrm{I})$, bicarbonate $(\mathrm{p}=0.0 \mathrm{II})$ and ESS $(\mathrm{p}=0.00 \mathrm{I})$, and rise in $\mathrm{PaO}_{2}(\mathrm{p}=0.004)$.

Abbreviations: ESS, Epworth sleepiness score; $\mathrm{NIV}$, noninvasive ventilation; $\mathrm{SEM}$, standard error of mean; $\mathrm{PaCO}_{2}$, arterial carbon-dioxide tension; $\mathrm{PaO}{ }_{2}$, arterial oxygen tension. 
however was significant from baseline to $5 \mathrm{D}(\mathrm{p}=0.011)$. HCVR is dependent upon $\mathrm{FEV}_{1}$ (significant linear regression, $\left.\mathrm{p}=0.001 ; \mathrm{r}^{2}=0.48\right)$, however there were no changes in $\mathrm{FEV}_{1}$. There was no significant change in intercept, or ventilation at a $\mathrm{PetCO}_{2}$ of $8 \mathrm{kPa}$.

\section{Respiratory muscle strength}

All 19 patients carried out noninvasive tests of muscle strength, 15 carried out invasive tests at baseline and D5, and 11 on all three occasions. Overall there were no significant changes in strength, and only a trend towards an increase in PeMax ( $p=0.06$, Figure 3). Comparing baseline and D5, there were significant increases in two measures of inspiratory muscle strength (SNIP, $\mathrm{p}=0.025$ and PiMax, $\mathrm{p}=0.027$ ) and a trend towards an increase in the third measure (Sniff Poes, $\mathrm{p}=0.071$ ). One measure of expiratory muscle strength increased (PeMax, $\mathrm{p}=0.033$ ) however another did not (Pga, $\mathrm{p}=0.44)$. There were no changes in volitional trans-diaphragmatic pressure (Sniff Pdi, $p=0.75)$ or nonvolitional transdiaphragmatic pressure (TwPdi 7 [5] on each occasion, $p=0.93$ ). Changes in muscle strength occurred independent of lung volumes; there was no change in FRC, and no correlation between the increase in PeMax and decrease in total lung capacity (TLC) $\left(\mathrm{r}^{2}=0.14\right.$; $\mathrm{p}=0.17$ at D5 and $\mathrm{r}^{2}=0.19 ; \mathrm{p}=0.10$ at $3 \mathrm{M}$ ).

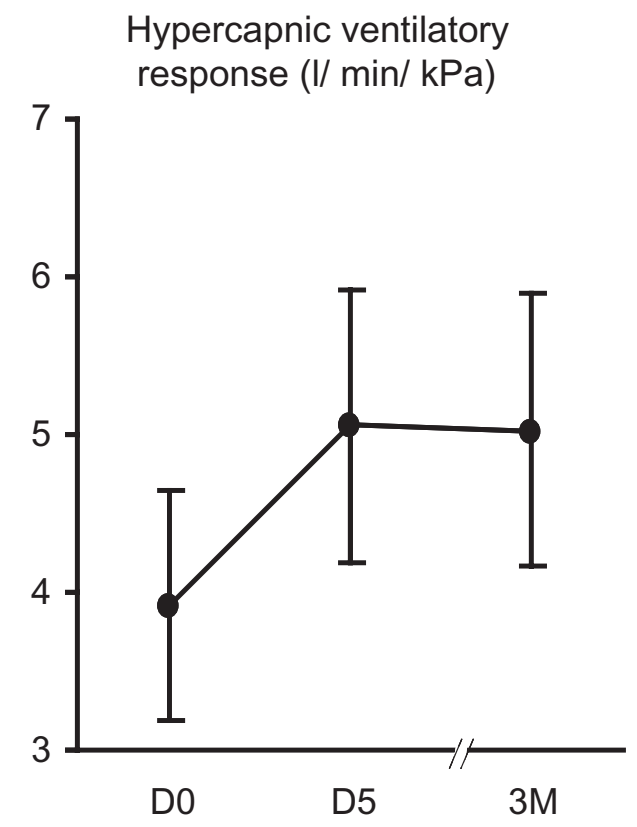

Figure 2 Effect of NIV on HCVR Mean (SEM) HCVR at D0,D5 and 3M is shown. There was no overall significant increase in $\operatorname{HCVR}(p=0.23)$, however there was a significant increase in HCVR from baseline to 5D when NIV use was good $(p=0.009)$.

Abbreviations: HCVR, hypercapnic ventilatory response; NIV, noninvasive ventilation; SEM, standard error of mean.

\section{Pulmonary mechanics}

Thirteen patients carried out lung volume measurements on all 3 occasions, and 16 patients at baseline and D5. There was a significant fall in TLC from 6.04 (1.65) L at baseline to $5.82(1.65) \mathrm{L}$ at D5 and $5.86(1.66) \mathrm{L}$ at $3 \mathrm{M}(\mathrm{p}=0.035)$. There was a trend towards reduction of residual volume (RV) $(\mathrm{p}=0.07)$ and no change in functional residual capacity (FRC) $(p=0.11)$, Figure 4, left panel. There was a significant decrease in gas trapping, (TLC minus alveolar volume) from baseline to three months ( $\mathrm{p}=0.04$, Figure 4 , right panel). There were no consistent changes in spirometry or carbonmonoxide transfer factor. There was a significant change in static chest wall compliance $(\mathrm{p}=0.01)$, with an increase at $\mathrm{D} 5$, and fall back to below baseline at $3 \mathrm{M}$, and no change in static lung compliance $(\mathrm{p}=0.13)$.

\section{Subset analysis}

Omitting 2 patients who were transferred from other hospitals did not change the main findings of the study. Both patients with and without OSA/cross-over syndrome had significant decreases in $\mathrm{PaCO}_{2}$ post-NIV, however only those with OSA/cross-over syndrome had an overall increase in $\mathrm{PaO}_{2}(\mathrm{p}=0.001$ versus 0.23$)$ and reduction in ESS $(p=0.004$ versus 0.08$)$, and increase in HCVR at D5 ( $\mathrm{p}=0.019$ versus 0.17$)$.

\section{Dose response}

In contrast to patients with restrictive disease, there was no linear regression between changes in $\mathrm{PaCO}_{2}$ or ESS and hours of use, however patients using NIV for more than 4 hours per night tended to have no change or an increase in HCVR and decrease in TLC, whilst those using it for less than 4 hours had no consistent changes (Figure 5, top panels). There was also a tendency for a fall in $\mathrm{PaCO}_{2}$ to be associated with an increase in HCVR and decrease in TLC (Figure 5, bottom panels). This was significant only at $3 \mathrm{M}$ for HCVR $\left(r^{2}=0.35 ; p=0.02\right)$.

\section{Discussion}

This study examines three hypotheses by which gas-exchange may improve following NIV in COPD patients with symptomatic hypercapnic respiratory failure: increased ventilatory sensitivity to $\mathrm{CO}_{2}$, increased respiratory muscle strength, and improved pulmonary mechanics. The findings support the first and third mechanisms, with an increase in HCVR, at least at D5, and decrease in TLC. This contrasts with our previous data in patients with restrictive disease, where increased HCVR alone was shown to be associated with NIV use. 


\section{Respiratory Muscle Strength $\left(\mathrm{cmH}_{2} \mathrm{O}\right)$}

Inspiratory

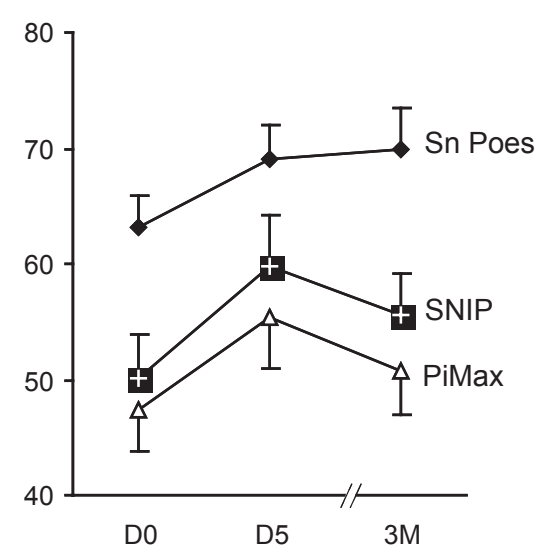

Expiratory

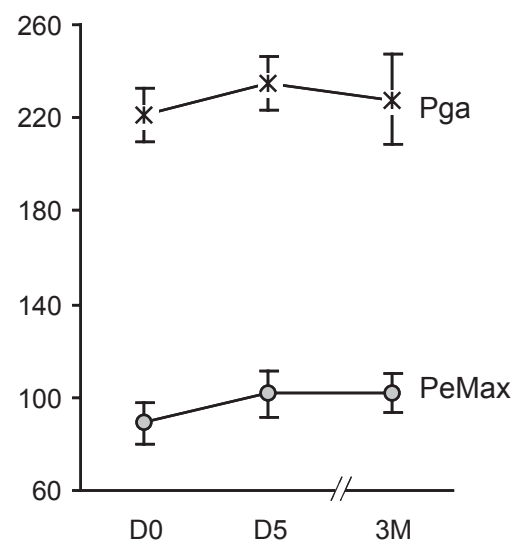

Diaphragmatic

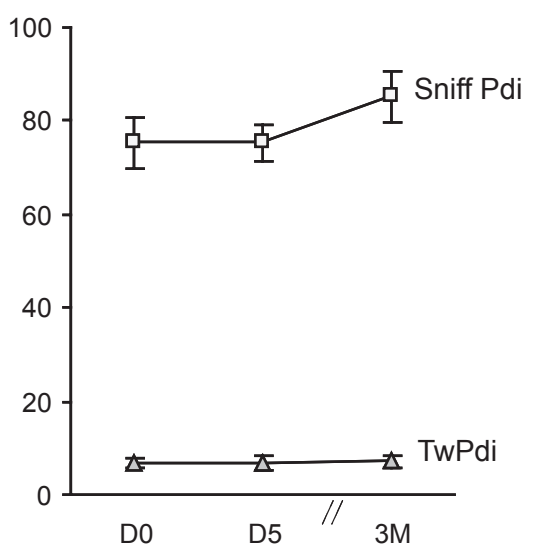

Figure 3 Effect of NIV on inspiratory, expiratory and diaphragmatic respiratory muscle strength. Mean (SEM) values at D0, D5, and 3M are shown.

Abbreviations: NIV, noninvasive ventilation; SEM, standard error of mean; Sniff Poes, sniff esophageal pressure; PiMax, maximum inspiratory pressure; SNIP, sniff nasal pressure; PeMax, maximum expiratory pressure; Pga, cough gastric pressure; Sniff Pdi, sniff transdiaphragmatic pressure; TwPdi, twitch transdiaphragmatic pressure.

Notes: Overall changes in respiratory muscle strength were not significant.

\section{Critique of the method}

Although our data have the merit of reflecting the 'real world', we acknowledge that the findings of our study are limited by the relatively small sample size, mixed nature of the population studied, poor average adherence rates and lack of a control group. It would have been preferable for patients to undergo a standardized run-in period for medical optimization before commencing NIV, and to have a randomized control group without NIV. Despite NIV in COPD not being standard treatment for 'all-comers', we did not consider it practical to delay treatment in this cohort, or admit patients to hospital without offering NIV. They had been referred by external respiratory specialists because of marked symptoms of hypoventilation, or because they were

\section{Lung volumes $(\mathrm{L})$}

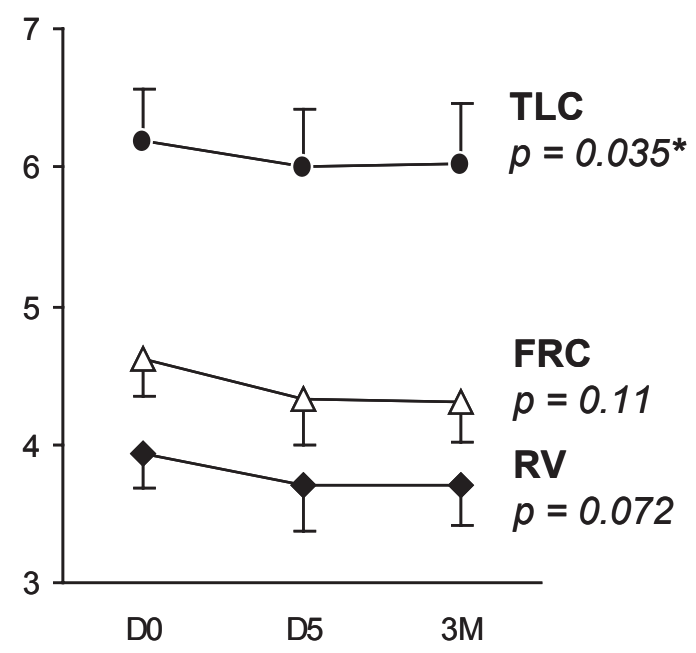

\section{Gas trapping (L)}

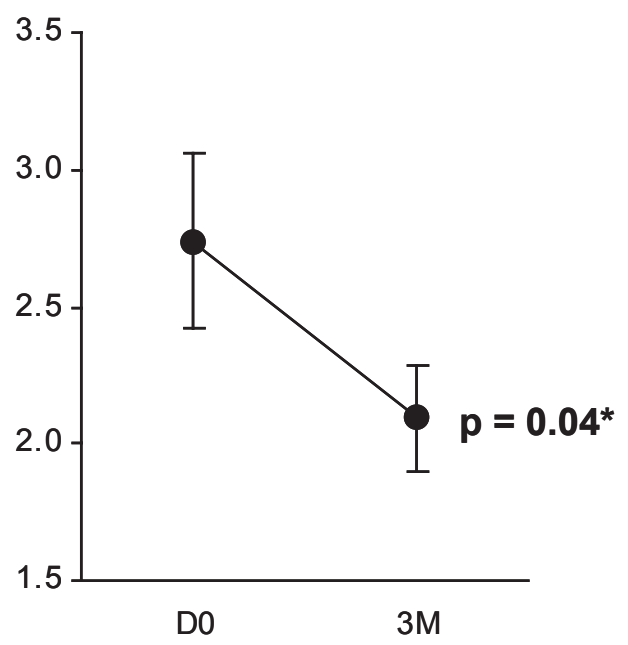

Figure 4 Effect of NIV on lung volumes (left panel) and gas trapping measured as TLC - alveolar volume, (right panel). Mean (SEM) values at D0, D5, and 3M are shown. The fall in TLC and gas trapping were significant $(P=0.035$ and 0.04 , respectively).

Abbreviations: NIV, noninvasive ventilation; SEM, standard error of mean. TLC, total lung capacity. 
$\triangle \mathrm{HCVR}$

$(\mathrm{l} / \mathrm{min} / \mathrm{kPa})$

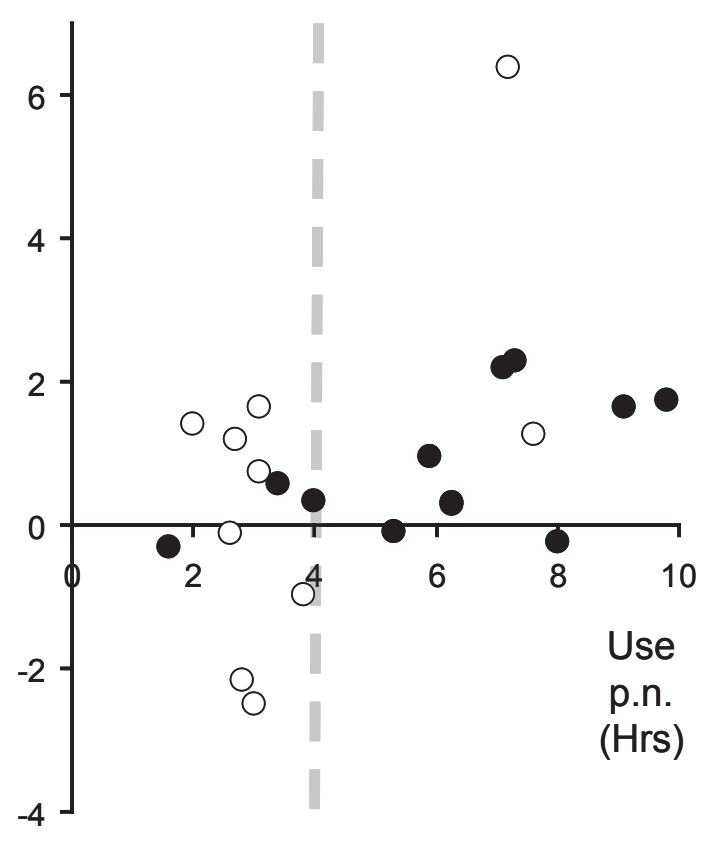

$\triangle \mathrm{TLC}$

(L)

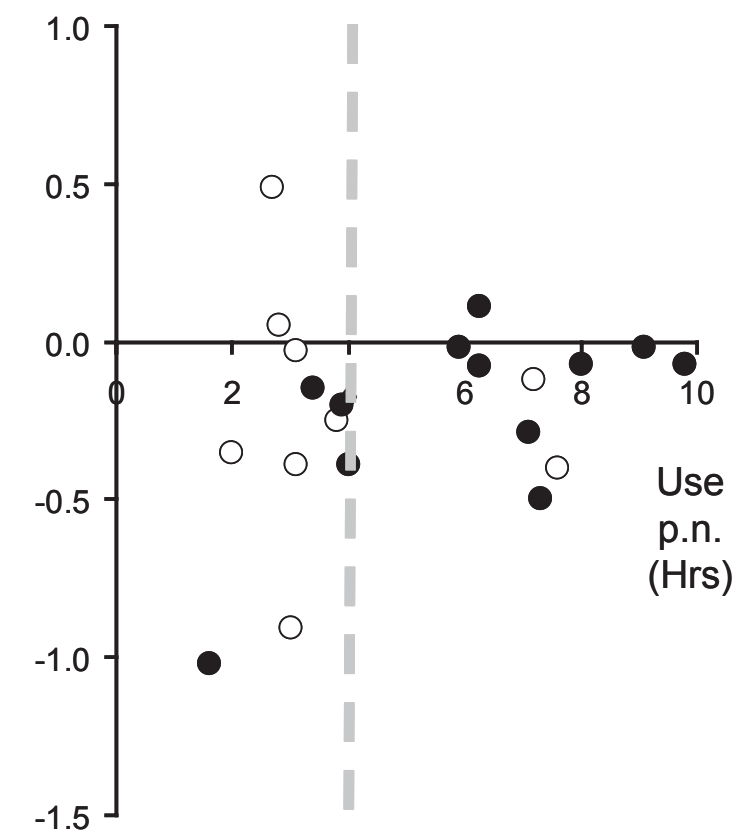

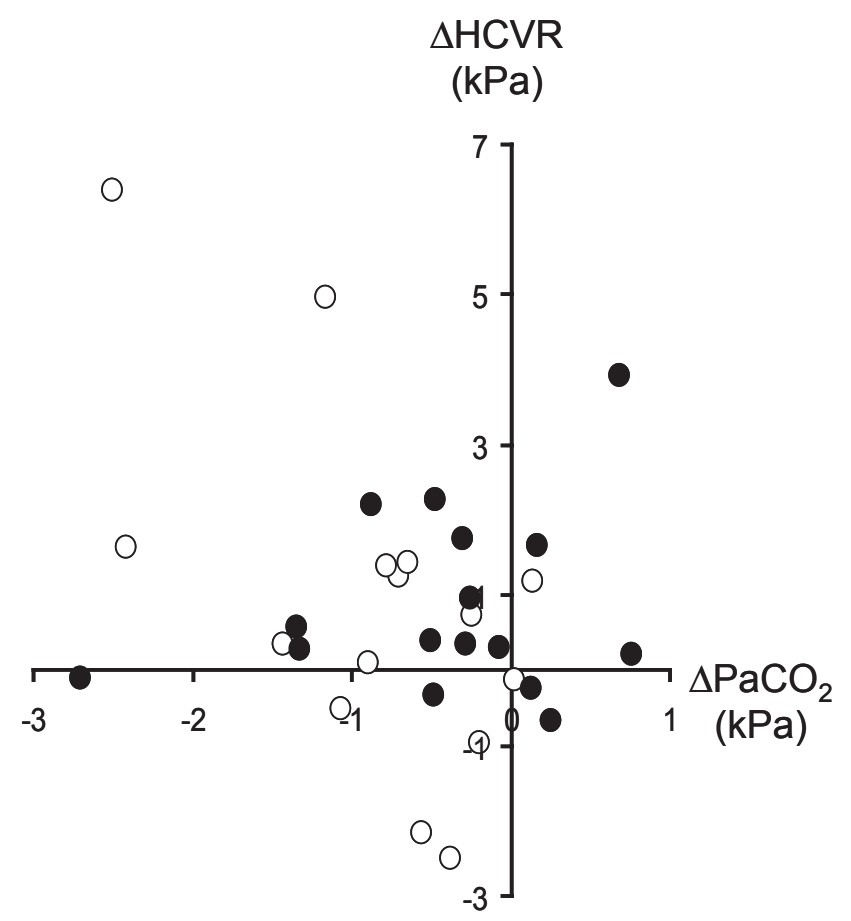

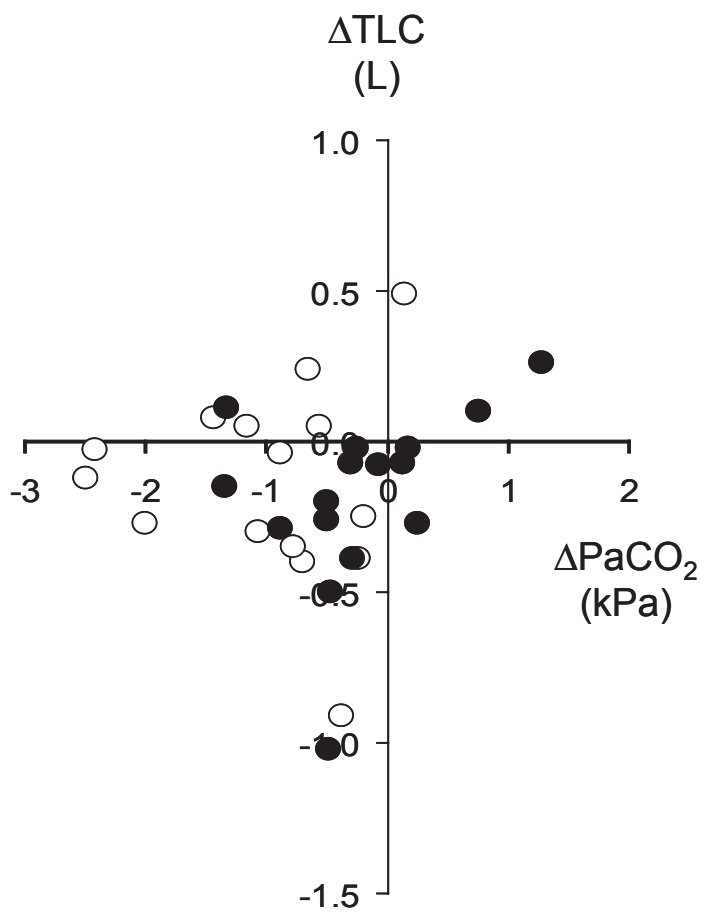

Figure 5 Changes in the hypercapnic ventilatory response (left panels) and TLC (right panels) versus mean hours of NIV use per night (top panels) and change in PaCO (bottom panels). Closed circles denote data at D5 and open circles at 3M. Dotted lines in the top panels indicate 4 hours of use per night.

Abbreviations: $\mathrm{HCVR}$, hypercapnic ventilatory response; $\mathrm{NIV}$, noninvasive ventilation; $\mathrm{PaCO}_{2}$, arterial carbon-dioxide tension; TLC, total lung capacity. 
unable to tolerate LTOT without ventilatory support $(n=7)$. Nevertheless in the light of our main conclusion we now believe a prospective randomized controlled trial would be appropriate given less good NIV adherence at 3 months.

\section{Significance of findings Use and efficacy of NIV}

Daytime arterial blood gases and subjective sleepiness improved significantly. In contrast to most previous studies, we did not attempt to dissect the relative contributions of OSA and COPD to hypoventilation since this is not usual in the UK. As in previous studies of COPD, (Leger et al 1994; Simonds and Elliott 1995) adherence to NIV decreased with time from 6.2 (3.7) to 3.4 (1.6) hours per night at D5 and $3 \mathrm{M}$, respectively, compared with 6.7 (1.9) to 4.2. (2.6) hours per night in patients with restrictive lung disease (Nickol et al 2005). Reasons for greater early use in our studies may include greater patient motivation due to high expectations of a new treatment, intensive support from the multidisciplinary team, and nurse led decisions regarding NIV start and stop times. Specific to COPD may be excess dyspnea and sputum production leading to poor interface tolerance, with little amelioration of these symptoms by NIV. In contrast, in restrictive disease, symptoms of hypoventilation predominate and NIV is usually effective in relieving these. Furthermore there is greater technical difficulty perfectly adjusting the ventilator for patient comfort in COPD due to intrinsic positive end-expiratory pressure and dynamic hyperinflation leading to increased work of breathing triggering the ventilator, and the requirement of a prolonged expiratory phase. Of note in our study patients with lower adherence to NIV reported more technical problem such as air leaks $(n=1)$ and synchronization difficulty $(\mathrm{n}=2)$.

\section{Increased ventilatory sensitivity to $\mathrm{CO}_{2}$}

At early follow-up increased HCVR supports the first hypothesis. At 3M this became nonsignificant, perhaps due to reduced NIV use. We speculate that increased HCVR enables a more appropriate increase in ventilation to occur in response to transient increases in $\mathrm{PaCO}_{2}$, so diminishing hypercapnia. Increased HCVR in turn is likely to be due to decreased $\mathrm{PaCO}_{2}$, either directly (Gibson 2006), or indirectly through decreased renal retention of bicarbonate. Increased bicarbonate reduces acid buffering capacity, resetting the chemoreceptors so they respond at lower $\mathrm{PCO}_{2}$ levels. An additional mechanism that may have contributed to the increase in HCVR is sleep consolidation. For example, use of CPAP (Moura et al 2001) or tracheostomy (Guilleminault and Cummiskey 1982) in OSA has been shown to increase HCVR, at least in hypercapnic patients (Berthon-Jones and Sullivan 1987). Only one previous study has examined HCVR post-NIV in COPD (Elliott et al 1991), and similarly then found no change in HCVR at 3M. They did, however, observed a significant correlation between decreased $\mathrm{PaCO}_{2}$ and increased ventilation at a $\mathrm{PetCO}_{2}$ of $8 \mathrm{kPa}$. We found a significant correlation between the fall in $\mathrm{PaCO}_{2}$ and increase in $\mathrm{HCVR}$ at $3 \mathrm{M}$, but not with the increase in ventilation at a $\mathrm{PaCO}_{2}$ of $8 \mathrm{kPa}$.

At $3 \mathrm{M}$ blood gases continued to improve despite less NIV use and no further change in HCVR. This may be due to another mechanism, such as progressive optimization of lung volumes. Alternatively increased HCVR may facilitate escape from the downwards spiral of ventilatory failure. There may be restoration of imbalance between high ventilatory load (increased airways resistance, positive end-expiratory pressure [PEEP], and dynamic hyperinflation), reduced respiratory muscle strength (functionally disadvantaged flattened diaphragm), and blunted ventilatory drive (renal retention of bicarbonate). Improved gas exchange might then be maintained even with less NIV use. This is speculative, and alternative causes of improvement to NIV must be considered such as intensive medical team exposure encouraging patients to adhere to medical therapy. Although patients appeared stable at study entry, it is possible that lack of baseline stability, with 'regression to the mean', may have contributed to the improvements seen during this study.

\section{Improved muscle strength}

The second hypothesis of relief of low frequency respiratory muscle fatigue is not supported. At D5 there were increases in two of three measures of inspiratory muscle strength and one of two measures of expiratory muscle strength. Some previous studies have also shown improvements in noninvasive measures of respiratory muscle strength (Marino and Braun 1982; Braun and Marino 1984; Zibrak et al 1986; Cropp and Dimarco 1987; Gutierrez et al 1988; Ambrosino et al 1990), but not others (Zibrak et al 1988; Elliott et al 1991; Lin 1996; Clini et al 2002). We found no change in the nonvolitional measure of muscle strength, TwPdi. A previous study, in which patients with poor NIV adherence were excluded from the analysis, has similarly shown no change in TwPdi (Schonhofer et al 2006). It is possible improved volitional measures observed in some studies simply reflects improved patient effort. Changes in respiratory muscle endurance following NIV have not previously been assessed, and may be of greater relevance than strength. 


\section{Decreased total lung volume}

Total lung capacity and gas trapping (TLC minus alveolar volume) decreased significantly, supporting the third hypothesis. Decreases in FRC and RV failed to reach significance ( $p=0.11$ and 0.065$)$, and there were no changes in spirometry, carbon-monoxide transfer or compliance. It may appear counter-intuitive that a positive pressure applied to the airway reduces TLC, however there are several plausible mechanisms. Firstly NIV may splint open airways, so maintaining them above their closing volume throughout expiration aiding emptying. Secondly, NIV could change breathing pattern leading to slower, deeper breaths and reducing hyperinflation, as has been shown in mechanically ventilated patients (Tuxen and Lane 1987) and in COPD patients during exercise (O'Donnell et al 2001). Lastly, NIV may reduce pulmonary engorgement, bronchial wall edema and surface tension forces, so improving small airway and alveolar patency.

Previous studies, so long as sufficient inspiratory pressures are used, have also shown reduced lung volumes (Budweiser et al 2005), with significant correlations between reduced $\mathrm{PaCO}_{2}$ and PEEP (Diaz et al 2002) or gas-trapping (Elliott et al 1991). As in our study, the majority of previous studies have shown no changes in spirometry (Braun and Marino 1984; Zibrak et al 1986, 1988; Elliott et al 1991; Lin 1996; Perrin et al 1997; Clini et al 2002; Schonhofer et al 2006). The reason for the isolated increase in static chest wall compliance in our study at D5 and decrease at $3 \mathrm{M}$ is not clear. No previous studies have measured static compliance, and one previous study measured dynamic compliance, and found it to be unchanged (Elliott et al 1991).

\section{Dose response}

Although we have not demonstrated a 'dose response' of NIV, it is likely to underlie improved gas-exchange since those using it for $<4$ hours per night had no consistent changes in HCVR or TLC, whereas those using it for $>4$ hours per night tended to have either no change or an increase. NIV 'dose' is likely to be more complex in obstructive than restrictive disease, with greater dependence on PEEP and patient-ventilator synchrony in addition to hours of use.

\section{Conclusions}

In conclusion, this study suggests improved gas-exchange and reduced sleepiness in symptomatic hypercapnic COPD patients initiated on NIV. It supports the hypothesis that improvements are brought about by optimization of pulmonary mechanics with reduced gas-trapping and increased ventilatory sensitivity to $\mathrm{CO}_{2}$. We acknowledge that these mechanisms are only speculative, given that the fall in TLC was small, and that HCVR was not significantly increased at 3M. Other unmeasured factors such as increased adherence to drug therapy may have been relevant at $3 \mathrm{M}$. Given that this is the case, then implementation of NIV should focus on appropriate setting of extrinsic PEEP and prolonged expiratory phase to maximize lung emptying. In addition, optimization of nocturnal $\mathrm{CO}_{2}$ control will aid chemoreceptors resetting to increase HCVR. The present data contrasts with those obtained from patients with restrictive lung disease, in which increased ventilatory sensitivity to $\mathrm{CO}_{2}$ but not optimization of pulmonary mechanics is the key mechanism.

\section{Acknowledgments}

The authors wish to thank Steve Heather and the sleep technicians for their care of patients when initiating NIV, Derek Cramer and Simon Ward and lung function staff for overseeing lung function testing and sleep studies. AN and this work was funded by a project grant from the British Lung Foundation, NH by the Dorothy Osbourne Legacy, NH by the Wellcome Trust, and MP's group from the European Union, (QLK6-CT-2002-02285). Some of these data have previously been presented in abstract form. The authors report no conflicts of interest in this work.

\section{References}

Ambrosino N, Montagna T, Nava S, et al. 1990. Short term effect of intermittent negative pressure ventilation in COPD patients with respiratory failure. Eur Resp J, 3:502-8

Berthon-Jones M, Sullivan C. 1987. Time course of change in ventilatory response to $\mathrm{CO}_{2}$ with long-term CPAP therapy in obstructive sleep apnea. Am Rev Respir Dis, 135:144-7.

Braun N, Marino W. 1984. Effect of daily intermittent rest of respiratory muscles in patients with chronic airflow limitation (CAL). Chest, 85(Suppl 595):59-60S.

Budweiser S, Heinemann F, Fischer W, et al. 2005. Long-term reduction of hyperinflation in stable COPD by non-invasive nocturnal home ventilation. Respir Med, 99:976-84.

Carroll N, Branthwaite M. 1988. Control of nocturnal hypoventilation by nasal intermittent positive pressure ventilation. Thorax, 43:349-53.

Clini E, Sturani C, Rossi A, et al. 2002. The Italian multicentre study on noninvasive ventilation in chronic obstructive pulmonary disease patients. Eur Respir J, 20:529-38.

Cropp A, Dimarco AF. 1987. Effects of intermittent negative pressure ventilation on respiratory muscle function in patients with severe chronic obstructive pulmonary disease. Am Rev Respir Dis, 135:1056-61.

Diaz O, Begin P, Torrealba B, et al. 2002. Effects of noninvasive ventilation on lung hyperinflation in stable hypercapnic COPD. Eur Respir J, 20:1490-8.

Elliott M, Mulvey D, Moxham J, et al. 1991. Domiciliary nocturnal nasal intermittent positive pressure ventilation in COPD: mechanisms underlying changes in arterial blood gas tensions. Eur Respir J, 4:1044-52.

Ellis E, Grunstein R, Chan S, et al. 1988. Noninvasive ventilatory support during sleep improves respiratory failure in kyphoscoliosis. Chest, 94:811-15. 
Gibson J. 2006. Mechanism of improvement of respiratory failure with non-invasive ventilation. Thorax, 61:545.

Guilleminault C, Cummiskey J. 1982. Progressive improvement of apnea index and ventilatory response to $\mathrm{CO}_{2}$ after tracheostomy in obstructive sleep apnea syndrome. Am Rev Respir Dis, 126:14-20.

Gutierrez M, Beroiza T, Contreras G, et al. 1988. Weekly cuirass ventilation improves blood gases and inspiratory muscle strength in patients with chronic air-flow limitation and hypercarbia. Am Rev Respir Dis, 138:617-23.

Hill N. 2000. Noninvasive ventilation has been shown to be ineffective in stable COPD. Am J Respir Crit Care Med, 161:689-91.

Kerby G, Mayer L, Pingleton S. 1987. Nocturnal positive pressure ventilation via nasal mask. Am Rev Respir Dis, 135:738-40.

Leger P, Bedicam J, Cornette A, et al. 1994. Nasal intermittent positive pressure ventilation. Long-term follow up in patients with severe chronic respiratory insufficiency. Chest, 105:1000-5.

Lin C. 1996. Comparison between nocturnal nasal positive pressure ventilation combined with oxygen therapy and oxygen monotherapy in patients with severe COPD. Am J Respir Crit Care Med, 154:353-8.

Marino W, Braun N. 1982. Reversal of the sequelae of respiratory muscle fatigue by intermittent mechanical ventilation. Am Rev Respir Dis, $125: 85$.

Meecham-Jones D, Paul E, Jones P, et al. 1995. Nasal pressure support ventilation plus oxygen compared with oxygen therapy alone in hypercapnic COPD. Am J Respir Crit Care Med, 152:538-44.

Moura S, Bittencourt L, Bagnato M, et al. 2001. Acute effect of nasal continuous positive air pressure on the ventilatory control of patients with obstructive sleep apnea. Respiration, 68:243-9.

Nickol A, Hart N, Hopkinson N, et al. 2005. Mechanisms of improvement of respiratory failure in patients with restrictive thoracic disease treated with non-invasive ventilation. Thorax, 60:754-60.
O’Donnell D, Revill S, Webb K. 2001. Dynamic hyperinflation and exercise intolerance in chronic obstructive pulmonary disease. Am J Respir Crit Care Med, 164:770-7.

Perrin C, Far YE, Vanderbos F, et al. 1997. Domiciliary nasal intermittent positive pressure ventilation in severe COPD: effects on lung function and quality of life. Eur Respir J, 10:2835-9.

Polkey M, Green M, Moxham J. 1995. Measurement of respiratory muscle strength. Thorax, 50:1131-5.

Read D. 1967. Clinical method for assessing the ventilatory response to carbon dioxide. Aust Ann Med, 16:20-32.

Robert D, Gerard M, Leger P, et al. 1983. [Ventilation mechanique a domicile des insuffisants respiratoires chroniques.] Rev Fr Mal Respir, 11:923-36.

Rossi A. 2000. Noninvasive ventilation has not been shown to be ineffective instable COPD. Am J Respir Crit Care Med, 161:688-91.

Schonhofer B, Polkey M, Suchi S, et al. 2006. Effect of home mechanical ventilation on inspiratory muscle strength in COPD. Chest, 130:1834-8.

Simonds A, Elliott M. 1995. Outcome of domiciliary nasal intermittent positive pressure ventilation in restrictive and obstructive disorders. Thorax, 50:604-9.

Tuxen D, Lane S. 1987. The effects of ventilatory pattern on hyperinflation, airway pressures, and circulation in mechanical ventilation of patients with severe airflow obstruction. Am Rev Respir Dis, 136:872-9.

Zibrak J, Federman E, Kwa S. 1986. Effect of negative pressure ventilatory assistance on pulmonary function in severe COPD. Chest, 89:515S.

Zibrak JD, Hill NS, Federman EC, et al. 1988. Evaluation of long-term negative-pressure ventilation in patients with severe chronic obstructive pulmonary disease. Am Rev Respir Dis, 138:1515-18. 